\title{
FORMAÇÃO INTEGRAL PARA O PROTAGONISMO RESPONSÁVEL: AS DIMENSÕES DA FORMAÇÃO DO JOVEM NO RECANTO MAESTRO
}

\author{
Ricardo Schaefer ${ }^{1}$
}

Resumo: Esta pesquisa de desenvolvimento teórico tem o objetivo de resgatar passagens teóricas e práticas expostas pelo Acad. Prof. Antonio Meneghetti relacionadas à formação de jovens no Centro Internacional de Arte e Cultura Humanista Recanto Maestro, cujos projetos educacionais estão baseados na pedagogia ontopsicológica e epicentrados na Antonio Meneghetti Faculdade. O escopo é identificar as principais dimensões que permitem uma formação integral para o desenvolvimento do protagonismo responsável nos jovens. As fontes de pesquisa englobaram materiais publicados em vida por Antonio Meneghetti, materiais inéditos pertencentes ao acervo audiovisual da Fundação Antonio Meneghetti e pesquisas anteriores que investigaram a temática. A partir desse levantamento, chegou-se a cinco dimensões que, desenvolvidas de modo conjunto, complementar e progressivo, permitem uma formação integral ao protagonismo responsável: o estudo, o trabalho, a alta moralidade, a ciência e a internacionalidade.

Palavras-chave: formação integral, protagonismo responsável, pedagogia ontopsicológica, formação de jovens, Antonio Meneghetti Faculdade, Recanto Maestro.

\section{Integral training for responsible protagonism: the dimensions of young} training in teacher recanto

Abstract: This theoretical development research aims to recover theoretical and practical passages exposed by Acad. Prof. Antonio Meneghetti related to the training of young people in the International Center for Art and Humanist Culture Recanto Maestro, whose educational projects are based on ontopsychological pedagogy and epicentrados in Antonio Meneghetti Faculty. The scope is to identify the main dimensions that allow an integral formation for the development of the responsible protagonism in the young. The research sources included materials published in life by Antonio Meneghetti, unpublished materials belonging to the audiovisual collection of the Antonio Meneghetti Foundation and previous research that investigated the theme. From this survey, five dimensions have been developed which, developed in a joint, complementary and progressive way, allow an integral formation to the responsible protagonism: study, work, high morality, science and internationality.

\footnotetext{
${ }^{1}$ Graduação em Jornalismo pela Universidade Federal de Santa Catarina (2007), pós-graduação em Gestão de Negócios pela Universidade Cidade São Paulo (2009) e em Ontopsicologia Social pela Universidade Estatal de São Petersburgo (2011), Mestrado em Comunicação Midiática pela Universidade Federal de Santa Maria (UFSM). Doutorando em Administração pela UFSM. Atualmente é Editor da Revista Performance Líder e Coordenador de Formação Empreendedora e Liderança (FOIL) da Antonio Meneghetti Faculdade (AMF).
} 
Keywords: integral formation, responsible protagonism, ontopsychological pedagogy, youth formation, Antonio Meneghetti Faculty, Recanto Maestro.

Resúmen: Esta investigación de desarrollo teórico tiene el objetivo de rescatar pasajes teóricos y prácticas expuestas por el Acad. (En inglés) Antonio Meneghetti relacionadas con la formación de jóvenes en el Centro Internacional de Arte y Cultura Humanista Recanto Maestro, cuyos proyectos educativos se basan en la pedagogía ontopsicológica y epicentrada en la Universidad de Antonio Meneghetti. El alcance es identificar las principales dimensiones que permiten una formación integral para el desarrollo del protagonismo responsable en los jóvenes. Las fuentes de investigación englobaron materiales publicados en vida por Antonio Meneghetti, materiales inéditos pertenecientes al acervo audiovisual de la Fundación Antonio Meneghetti y investigaciones anteriores que investigaron la temática. A partir de ese levantamiento, se llegó a cinco dimensiones que, desarrolladas de modo conjunto, complementario y progresivo, permiten una formación integral al protagonismo responsable: el estudio, el trabajo, la alta moralidad, la ciencia y la internacionalidad.

Palabras-claves: Formación integral, protagonismo responsable, pedagogía ontopsicológica, formación de jóvenes, Antonio Meneghetti Facultad, Recanto Maestro.

\section{INTRODUÇÃO}

"Existe um ponto fundamental que interessa a todos: a nossa juventude... Para onde está caminhando hoje? Que potencial possui? E o que estamos fazendo para os nossos melhores jovens?" É com estes questionamentos que Antonio Meneghetti (2015a, p. 83) abre o seu pronunciamento na cerimônia de inauguração da Antonio Meneghetti Faculdade (AMF), em 2008, no Centro Internacional de Arte e Cultura Humanista Recanto Maestro. O patrono da instituição de ensino que leva o seu nome faz, nesta fala de abertura, uma chamada à formação à responsabilidade: "Esta escola, este projeto, quer dar uma possibilidade de responsabilidade. Isso é, chamarmos novamente, recordarmos desta palavra: responsabilidade" (MENEGHETTI, 2015a, p. 84).

Passados 10 anos da sua fundação, o projeto cresceu e evoluiu. Seguindo a psicologia da árvore, a partir de uma semente plantada, desenvolveu-se segundo as oportunidades e possibilidades sempre em mutação do contexto em que existe. O desafio nesse processo, como indivíduo ou como grupo de indivíduos organizados em um projeto 
ou sociedade - tendo o livre arbítrio que não possui uma árvore - é crescer sempre em conformidade à própria identidade. Um projeto pode crescer seguro e fiel à sua essência se seguir um movimento constante de centripetação e centrifugação: na medida em que se expande externamente, reforça o seu núcleo ou essência, que por sua vez dá estímulo e força para uma nova expansão, e assim por diante.

Partindo desse princípio, esta pesquisa de desenvolvimento teórico tem o objetivo de resgatar passagens teóricas e práticas expostas por Antonio Meneghetti relacionadas à formação de jovens no Centro Internacional de Arte e Cultura Humanista Recanto Maestro a fim de identificar as principais dimensões que permitem uma formação integral para o desenvolvimento do protagonismo responsável. As fontes de pesquisa englobaram materiais publicados em vida por Antonio Meneghetti, materiais inéditos pertencentes ao acervo audiovisual da Fundação Antonio Meneghetti e pesquisas anteriores que investigaram esta temática.

Em uma fala sobre as especificidades que diferenciam a AMF das outras instituições de ensino, realizada por Antonio Meneghetti em 2012, cujos trechos foram transcritos de modo inédito neste artigo, o fundador do Recanto Maestro e patrono da AMF expõe:

\footnotetext{
Vocês fazem milagre... E isso é resultado de uma formação, de uma formação contínua, da qual a faculdade é a expoente, é a ponta de diamante de uma formação que começa pela base acadêmica em diversos campos. Mas, junto a essa estrutura-base, nós inervamos dentro uma preparação complementar que dá uma eficiência em $360^{\circ}$. (MENEGHETTI, 2012, transcrição de áudio)
}

A partir dessa exposição e de outros textos e pronunciamentos de Antonio Meneghetti sobre a formação de jovens na AMF e no Recanto Maestro, chegou-se nesta pesquisa a cinco dimensões que, desenvolvidas de modo conjunto, complementar e progressivo, permitem uma formação integral ao protagonismo responsável. Essas dimensões foram identificadas como estudo, trabalho, alta moralidade, ciência e internacionalidade, e são descritas a seguir.

\section{A DIMENSÃO DO ESTUDO}


A dimensão do estudo na formação dos jovens no Recanto Maestro é epicentrada na Antonio Meneghetti Faculdade, que se configura como o coração do projeto. Autorizada pelo Ministério da Educação em 2008, é hoje uma instituição de ensino superior pioneira no Brasil por utilizar a Ontopsicologia como ciência epistêmica e interdisciplinar em todos os seus cursos de graduação, pós-graduação e extensão, e também pioneira no mundo por criar um curso de Bacharelado em Ontopsicologia.

O primeiro aspecto fundamental que garante a dimensão do estudo são os professores, como destaca Meneghetti (2012) ao descrever as especificidades que diferenciam a AMF das demais instituições de ensino superior:

\begin{abstract}
Primeiro, usamos professores que, além de terem uma formação específica, acadêmica, nos seus setores, nos seus campos, demonstraram e demonstram uma alta eficiência de ganho econômico nas suas empresas, nos seus empreendimentos, nas suas atividades profissionais de destaque. Portanto, junto à formação acadêmica, e à maturidade humana da pessoa, acolhemos também o terceiro critério da eficiência, aquele do ganho econômico. (MENEGHETTI, 2012, transcrição de áudio)
\end{abstract}

Os professores que atuam na AMF devem demonstrar, portanto, além da formação acadêmica e maturidade como pessoa, eficiência de ganho econômico nas suas empresas ou atividades profissionais. Essa característica está relacionada a um mote da instituição de que "só ensina quem faz", ou seja, pode ensinar o outro aquele que é, sabe e faz. "Esse critério nasce da constatação de que um indivíduo não pode ensinar o que não é; do contrário, oferece um blefe, um falso que desrespeita a valiosa tarefa de contribuir para a formação de um indivíduo" (PETRY et. al., 2011, p. 84).

Tomando como exemplo a área econômica, Meneghetti (2013b) aponta como muitos daqueles que escreveram sobre sua área eram intelectuais privados da práxis econômica, ao passo que "aqueles que gerenciaram e viveram com sucesso a economia real não escreveram nada da sua experiência" (MENEGHETTI, 2013b, p. 12). As características dos professores AMF anteriormente descritas buscam desfazer esse hiato ou contraposição, unindo no seu corpo docente a formação acadêmica e intelectual à prática de mercado e resultado econômico.

Além da formação técnica em suas respectivas áreas de graduação, os alunos cursam disciplinas de formação empreendedora e liderança que utilizam a metodologia FOIL (Formação Ontopsicológica Interdisciplinar Liderística). Nessas disciplinas se trabalha a 
técnica de personalidade e se desenvolve a forma mentis dos jovens, entendida como a adequada mentalidade, a adequada atitude que um jovem deve ter para se desenvolver no mercado de trabalho, ganhando "a excelência da própria dignidade, da sua autonomia econômica e o do seu liderismo" (MENEGHETTI, 2013b, p. 25).

\begin{abstract}
São jovens que entram no mundo do trabalho para aprender de modo superior o serviço, para a sua contribuição qualificada sob diversos aspectos e para chegar, um dia, a serem os chefes. (...) Ensina-se uma técnica de personalidade, entendida como aquele savoir-fare que é a inteligência centrada na ação específica de serviço à empresa e em que a pessoa é fundamental e determinante. (MENEGHETTI, 2013b, p. 24)
\end{abstract}

Trabalhando a forma mentis dos jovens em paralelo à formação técnica específica, busca-se progressivamente desenvolver neles uma competência competitiva em suas áreas de atuação profissionais. Competência competitiva enquanto capacidade de saber fazer algo específico que permite inicialmente a criação de uma base econômica e de autossustento, até se chegar ao "primado de saber e fazer uma profissão específica" (MENEGHETTI, 2016, p. 74).

Essa formação é também contínua, do tipo life long learning, tendo em vista que a velocidade das modificações socioeconômicas em que estamos hoje inseridos requerem dos profissionais uma "atualização contínua das competências e habilidades" (MENEGHETTI, 2009, p. 12). O life long learning, ou o aprender durante toda a vida, deve ser tarefa de cada profissional, buscando uma contínua aquisição e renovação de conhecimentos e habilidades. Ao se criar a cultura do aprendizado contínuo, é possível atualizar constantemente os próprios modelos mentais, proporcionando a manutenção da atividade profissional no mercado competitivo em contínua evolução. É também por meio do life long learning que a atualização dos modelos mentais pode proporcionar contrahábitos positivos, possibilitando o desenvolvimento criativo e a competência competitiva (WAZLAWICK, 2014).

Exemplos de grandes lideranças de diferentes áreas e diferentes culturas são usados para ilustrar e exemplificar esse percurso formativo. Grandes homens de todos os tempos começaram pequenos e construíram progressivamente a própria grandeza, forjando a sua competência competitiva: 


\begin{abstract}
A história dos grandes vem da pobreza, do sacrifício, não vem de famílias nobres, ricas. Vem de jovens inteligentes que, na dificuldade, reagiram e fizeram a si mesmos como um valor social, segundo suas possibilidades. As irmãs Fontana morriam de fome... Etro, outro exemplo, foi certa vez para Caxemira, apaixonou-se pelas cabras, pensou no negócio e criou a Etro. Peguemos ainda Valentino, um pequeno artesão que trabalhava como alfaiate próximo a um grande mestre, Lítrico. Porém, Valentino passava horas cortando, costurando, fazendo. Ou seja, isto é liderança: qualquer coisa que se faça, deve saber fazer melhor que os outros, se você quer a realização do verdadeiro de si mesmo. (MENEGHETTI, 2015b, p. 98)
\end{abstract}

O objetivo dessa formação é que os melhores alunos possam alcançar os melhores postos de trabalho e de função social, não apenas no Brasil, mas - a médio e longo prazo também internacionalmente, conforme almejou o idealizador do projeto:

\footnotetext{
Nós somos todos interessados em dar aos melhores diplomados um posto elevado de trabalho nas empresas mais avançadas no Brasil e no mundo. Fazemos isso para os melhores estudantes que realizam a maturidade integral. Não fazemos apenas pelo seu interesse, mas também por um intrínseco ganho de toda a opera que nós desenvolvemos. (MENEGHETTI, 2012, transcrição de áudio)
}

Cria-se desse modo um impacto vivo entre os jovens e as organizações, entre os jovens e o mercado, entre os jovens e a sociedade. Demonstra-se através dessa formação “o que é necessário para entrar como protagonista no mundo do trabalho e saber fazê-lo bem. Este é o ponto: saber dar aquele tipo de serviço que o empregador gratifica com dinheiro, com respeito e com carreira" (MENEGHETTI, 2013b, p. 24).

\title{
3. A DIMENSÃO DO TRABALHO
}

O desenvolvimento da competência competitiva descrito anteriormente é também realizado por meio de trabalho. Não é suficiente a formação teórica em sala de aula. $\mathrm{O}$ jovem precisa também se experimentar e se formar por meio da prática. Nesse sentido, o trabalho é uma dimensão fundamental.

Com o trabalho desenvolve-se, além do saber fazer, um outro conceito-chave da FOIL: o saber servir. Para Meneghetti (2013b), o líder é aquele que melhor sabe servir: "pode comandar somente aquele que sabe servir e conhece mais do que os outros, para os outros" (MENEGHETTI, 2013b, p. 17). Para desenvolver a liderança, portanto, o jovem deve desde cedo aprender a arte do saber servir, das pequenas às grandes coisas. 
No interior da moral, nós ensinamos que se torna líder na medida em que se sabe servir, porque o cliente é a coisa mais importante. Então alguém que sabe servir o cliente realiza o próprio sucesso. Portanto, para ele é importante também o trabalho e a capacidade de deferência, de respeito pelos outros, mas sobretudo aquele de saber fazer, qualquer coisa, mas saber fazê-la bem. (MENEGHETTI, 2012, transcrição de áudio)

E para chegar à excelência do saber servir aos clientes, à excelência da própria atuação e prestação profissional, o jovem é estimulado no projeto Recanto Maestro, por meio do trabalho, a desenvolver competências e habilidades começando por tarefas basilares.

Iniciam fazendo pequenas tarefas caseiras ou rotineiras: limpeza geral, auxílio na cozinha, jardinagem, carpintaria etc. Além disso, todos são responsáveis pela ordem e higiene de suas áreas privativas. Um jovem não pode pretender-se líder se antes não souber tomar conta do pequeno ambiente onde vive, onde dorme. (PETRY et. al., 2011, p. 82)

Essas atividades de base têm um triplo escopo: 1. ensinar ao jovem coisas elementares do próprio existir, fundamentais para construir a própria autonomia; 2. introduzir os jovens às responsabilidades civis cotidianas; 3. iniciar uma experimentação sobre suas tendências, suas inclinações naturais, seus maiores interesses.

É o início do saber fazer, porque o aprendizado não dá saltos. Esse princípio é muito claro na matemática, na qual é evidente que não é possível resolver uma equação complexa sem antes aprender as operações primárias. A mesma lógica é válida para as atividades profissionais: o grande engenheiro deve entender como se faz e se aplica o cimento; o grande estilista deve saber como é o caimento do tecido nos diferentes cortes possíveis; o grande cozinheiro deve conhecer as reações do alimento diante das diferentes temperaturas. $\mathrm{O}$ mercado de trabalho está repleto de diplomados que não sabem o á-bê-cê prático da própria profissão e essa é uma carência que tem grande impacto na empregabilidade, na estabilidade do emprego e no crescimento de carreira. (PETRY et. al., 2011, p. 82)

Esses trabalhos e atividades iniciais mais simples evoluem para atividades mais estruturadas e de maior responsabilidade, sempre em uma ordem crescente de dificuldade e segundo as suas tendências, áreas onde o jovem demonstra maior interesse e aptidão. Introduz-se o jovem, desse modo, no mundo do fazer, para o qual é necessária uma contínua preparação. Esse aspecto, além endereçar o jovem a uma futura profissão que possibilite a base econômica, "também contribui para a formação de uma personalidade 
social, na medida em que, da atividade laboral, o jovem aprende a participar, trocar, criar, construir em conjunto" (PETRY; OLIVEIRA; SCHAEFER, 2011, p.22).

Wazlawick (2014) também destaca que, para desenvolver a própria ambição e capacidade, no início o jovem deve fazer muita prática, deve assimilar tantas estradas, operar sobre si mesmo, para saber qual estrada tomar. Deve compreender como ser eficaz, como estar tecnicamente preparado, para aquilo que um dia será o seu futuro. Por isso, a formação no trabalho, a técnica, a escola, todos os conhecimentos teóricos e práticos a respeito das áreas de interesse de cada um são fundamentais. O jovem deve agir, experimentar-se, resolver e solucionar, pois o maior conhecimento, habilidades e competências advêm com a ação. Aqui encontra-se a dimensão do fazer (WAZLAWICK, 2014).

A partir dessa iniciação no mundo do trabalho, o jovem começa a desenvolver também a possibilidade do autossustento, um dos primeiros deveres de todo jovem, que lhe consente "ganhar a própria autonomia e a própria liberdade de ação" (ROCCO, 2006, p. 9). O primeiro ponto ao qual um jovem deve se referir constantemente, para além das tantas questões que deve administrar (corpo, família, amigos, universidade etc.), "é a necessidade de ter em vista o próprio espaço, a referência de segurança econômica. A base econômica é a liberdade, é a autonomia, é o direito de ser como você é" (MENEGHETTI, 2013b, p. 37).

Trabalhando nas organizações e empresas que compõem o projeto Recanto Maestro, partindo de funções iniciais e de base descritas anteriormente, o jovem progressivamente passa a novas e maiores tarefas e funções:

\footnotetext{
Na medida em que o jovem aprende e se desenvolve, passa por diferentes funções dentro das empresas e gradativamente aumenta a dificuldade e a relevância das suas tarefas: recepção, secretaria, organização de eventos, atividades administrativas, financeiras, até atingir funções de liderança naquele âmbito onde demonstrou maior habilidade, interesse e coerência de investimento. Essa trajetória dá ao jovem uma visão do todo e prepara para uma futura capacidade de gestão, pois saberá como avaliar, orientar e conduzir quando chegar o seu momento de liderar. (PETRY et. al., 2011, p. 82)
}

Além disso, o trabalho não é apenas importante para a aprendizagem de uma técnica ou de uma profissão. O trabalho desempenha um papel fundamental na formação do ser humano na medida em que é pelo trabalho que o homem, como ser social, passa de sua origem baseada nos instintos a uma produção como gênero humano. Esse conceito já era 
presente na formação clássica do homem grego, período em que o valor do trabalho era um caminho fundamental para se alcançar a virtude ou areté (PELLEGRINI; PETRY, 2010; PETRY et. al., 2011). Desse modo, o trabalho passa a ser uma dimensão essencial para a realização do ser humano.

\section{A dimensão da alta moralidade}

Outra dimensão fundamental para o desenvolvimento integral dos jovens que estudam e trabalham no Recanto Maestro é a alta moralidade, que compreende a disciplina, a organização e limpeza, a questão estética, o contato com o ambiente e uma convivialidade sadia. Meneghetti (2012) assim descreve essa dimensão:

Existe indiretamente uma base de disciplina. Em toda a faculdade, não existe nenhuma direção ideológica, somente a formação à eficiência, porém existe todo um background, todo um húmus de alta moralidade, a fim de consentir ao jovem desenvolver aqueles valores que depois o farão grande um dia na sociedade, e possivelmente evadir de todas as superficialidades que frequentemente lesam, invalidam a estrutura mais alta, mais séria do jovem. Portanto existe essa indireta moralidade de seriedade humanista sob todos os pontos de vista. (MENEGHETTI, 2012, transcrição de áudio)

É por meio da disciplina, da organização e limpeza do próprio espaço em que habita e trabalha, da produção da própria comida, da dialética e convívio sadio com seus pares, da superação das dificuldades inerentes à saída da casa dos pais e do início da vida acadêmica e da vida profissional, que o jovem desenvolve uma importante característica do ser humano: a responsabilidade.

Os grandes gênios de todos os tempos sempre nasceram e se educaram no sacrifício. Quem de vocês, na história, consegue encontrar um gênio, reconhecido como tal, que venha de uma ótima família? Não o encontramos jamais. Existe uma parte de sacrifício que nós genitores, nós educadores, não devemos tirar dos nossos filhos, porque é a prova onde eles devem vencer, devem conseguir resolver os seus pequenos problemas, pois a solução dos pequenos problemas é a garantia de uma maturidade de ação. Isto é, com os nossos sistemas educacionais, não devemos tirar a "academia de vida" dos nossos filhos. Devemos parar com o excessivo bem-estar, o excessivo assistencialismo, porque o nosso assistencialismo - que é feito por amor, pois não queremos que os nossos filhos sofram - faz com que cresçam estúpidos, cresçam esquizofrênicos. (...) Esta escola, este projeto, quer dar uma possibilidade de responsabilidade. Isto é, chamarmos novamente, recordamos desta palavra: responsabilidade. (MENEGHETTI, 2015a, p. 84) 
Para se desenvolver uma competência competitiva é também fundamental o estilo de vida. O jovem deve ter uma vida coerente em tudo o que é o seu espaço de ação, da moradia ao ambiente de trabalho, dos espaços de convívio às relações de prazer. "Existe constantemente uma situação de apoio no viver cotidiano (comer, dormir etc.) e para o sujeito é importante que as próprias coisas sejam representativas de uma sua eficiência" (MENEGHETTI, 2016, p. 38).

Ao fazer a análise do filme Educação (2009), e indicando que a atmosfera e o estilo de vida dos personagens pudesse ser uma referência à formação na AMF, Meneghetti (2011a) explicita:

\footnotetext{
Uma coisa é certa. A elegância, a dignidade de uma pessoa implica um espaço de veneração, de respeito por todos. $\mathrm{E}$ isso ajuda a ter uma grande responsabilidade sobretudo para si mesmo, a ter cultura, a ter uma contínua educação, de como vestir, como comer, como dormir, ou seja, manter-se em um espaço de uma pessoa inteligente. Se você vive em um espaço sujo, desordenado, também você se mistura à desordem, à sujeira. (...) Existe um estilo que deve ser aprendido, caso se queira chegar à dignidade, à superioridade de um dia ser líder no próprio campo. (MENEGHETTI, 2011a, transcrição de áudio)
}

Nessa dimensão está contida também a prática do esporte. No curso da história, a importância das atividades motoras na formação global do ser humano foi reconhecida em muitas épocas. Na formação dos jovens, o esporte e toda espontaneidade de jogo com movimento físico e contato devem ser encorajados, sobretudo aqueles de grupo, visto que permite um sadio metabolismo de interação e crescimento. Os jogos e práticas sobretudo de grupo são uma atividade de descarga, satisfação, introjeção do real e também da individuação diante de si mesmo e do mundo. Favorecem também aos jovens confidência e competência com a socialidade (ANTONIO MENEGHETTI FACULDADE, 2017).

O projeto Recanto Maestro, assim como outros centros criados por Antonio Meneghetti em várias partes do mundo, é desenvolvido em um ambiente ecologicamente saudável e estimulante. Tais ambientes são denominados centros ecobiológicos, onde é possível combinar as ações urbanísticas com o desenvolvimento humano. "O ser humano, em contato ativo com ambientes desse tipo, construindo uma horta, participando da vindima, sendo responsável pelo seu pequeno ambiente, não só retoma a intimidade com seu corpo e sua natureza, como aprende a se relacionar com o ambiente externo de forma harmônica e respeitosa" (PETRY; OLIVEIRA; SCHAEFER, 2011, p.22). Meneghetti (2011b) destaca que o contato com a terra fornece a primeira forma de pedagogia, 
possibilitando a retomada do contato com o universo natural, do qual todo ser humano deriva, porque também o ser humano é natureza.

Um contexto ecobiológico como Recanto Maestro proporciona uma integração entre homem e natureza em recíproca vantagem, favorecendo desse modo o processo de ensino e aprendizagem e a produtividade profissional. Todas as grandes culturas do passado sabiam da importância e da influência que o ambiente circundante exerce sobre o ser humano e seu convívio em sociedade.

\begin{abstract}
Não por acaso, os grandes mosteiros beneditinos, ou algumas moradas de grandes reis ou imperadores, eram construídos em lugares particularmente vitais, enquanto as prisões se localizavam em terras áridas, sombrias, onde as plantas não cresciam e os animais não permaneciam. Nosso planeta tem seus pontosforça, seus lugares mais fortes, mais vitais, mais adequados ao convívio humano e mais favoráveis ao seu desenvolvimento. Assim como cada planta precisa de um certo tipo de solo e de ecossistema, também o ser humano pode ser positivamente ou negativamente estimulado pelo ecoambiente que frequenta. É o antigo conceito romano de genius loci, o gênio do lugar, que define lugares precisos onde a natureza humana se reforça e se recompõe; é a melhor terra para aquela espécie de individuação. (PETRY, et. al., 2011, p. 80)
\end{abstract}

Criou-se portanto no Recanto Maestro um novo modelo de educação ambiental capaz de conjugar as intervenções urbanísticas e arquitetônicas com o desenvolvimento humano. Essa proposta ecobiológica permite saber viver a própria vida com qualidade, em osmose com o ecossistema naturístico. Esse modo de educação ambiental permite ao ser humano uma relação autônoma de saúde, estética e humanismo qualificado de recíproco respeito entre as pessoas e as culturas (BAZZO et. al., 2011).

\begin{abstract}
A natureza já é perfeita e coloca-nos na ocasião de nos fazermos perfeitos. Portanto, no âmbito do nosso trabalho e das relações cotidianas, sempre devemos procurar melhorarmos a nós mesmos e as coisas que temos, porque enquanto as melhoramos, elas nos geram em um horizonte superior. Enquanto você ajuda as coisas, as coisas ajudam você; enquanto você faz coisas, as coisas fazem você: é uma relação metabólica em que o sujeito realiza coisas e estas realizam o sujeito. (MENEGHETTI, 2011b, p. 274).
\end{abstract}

\title{
5. A dimensão da ciência
}

Com relação à dimensão da ciência na formação dos jovens no Recanto Maestro, a Ontopsicologia permite desenvolver a capacidade de individuar o nexo ontológico, permitindo uma formação global e integral da pessoa. Junto à formação técnica, junto à 
formação profissional, a Ontopsicologia - enquanto base científica interdisciplinar dessa formação - permite o desenvolvimento do valor e da dignidade da pessoa, do indivíduo.

Em paralelo à formação acadêmica e profissional, portanto, ocorre a formação da personalidade integral do jovem por meio da metodologia ontopsicológica. Essa formação existencial auxilia o jovem a compreender quem é e como pode desenvolver historicamente a própria identidade, a própria ambição, o próprio potencial de natureza.

\begin{abstract}
A primeira coisa é descobrir a própria ambição. Na sua estrada, de modo virtual, você já nasce com um projeto. Então, está aqui o primeiro ponto forte da Ontopsicologia: observa no sujeito qual é o seu projeto. E, para um jovem, começar já conhecendo isto é uma grande vantagem, é fundamental. Quantos erram a estrada, chegam aos 40 anos e dizem: "Ah, se tivesse feito diferente...". Em todas as escolas deveria ser assim, porque já o encaminhariam para onde existe a predisposição por natureza. (BERNABEI, 2011, p. 64)
\end{abstract}

A formação personológica baseada na metodologia ontopsicológica consiste em desenvolver ao máximo as potencialidades de cada indivíduo. Considerando que a personalidade é o resultado de um temperamento natural e de uma particular estruturação lógico-histórica definida caráter, é frequente a constatação de personalidades limitadas aos seus scripts, aos seus primitivos modelos de agir, pensar e sentir. Muitas vezes uma pessoa deseja fazer o bem e distinguir-se dos outros, "mas experimenta a amargura da derrota enquanto fez tudo aquilo que é previsto pelos estereótipos sociais, mas não fez quase nada para a intrínseca necessidade da sua natureza, que ela mesma desconhece" (MENEGHETTI, 2011b, p. 29). Para desenvolver a personalidade é necessário identificar a exigência instintiva daquele específico projeto, daquele específico indivíduo e, depois, encontrar a ação técnica, a solução racional de como atuar tal exigência, considerando a situação, o ambiente e o contexto em que ele se encontra (PETRY, OLIVEIRA, SCHAEFER, 2011).

Com a ciência ontopsicológica, além da formação profissional, acrescenta-se um processo de responsabilização pessoal, para que o indivíduo aprenda não só o exercício da profissão, mas aprenda melhor como construir a evolução da sua pessoa (VIDOR, 2016). Aplicada no campo da formação de jovens, a real novidade da Ontopsicologia é a descoberta do critério-base de natureza ou Em Si ôntico. Uma vez individuado esse critério, "é possível fazer uma pedagogia que consinta o desenvolvimento do projeto de natureza, e obtém-se como resultado um indivíduo, antes de tudo sadio e, depois, capaz de realizar a própria existência de modo criativo" (MENEGHETTI, 2014b, p. 235). 
Para se alcançar estes resultados, são realizados atividades e cursos de formação ontopsicológica que dão ao jovem a direção na busca pela própria identidade. Ensinam-se as três descobertas da Ontopsicologia, a formação da personalidade, as características do jovem líder, o equilíbrio da dupla moral, a importância e o valor de ser a si mesmo. "De acordo com os rigores metodológicos e os requisitos profissionais necessários para a aplicação de cada técnica, são realizadas cinelogias, imagogias, consultorias de autenticação, melolísticas e melodances, residences de autenticação, ou seja, são utilizados os instrumentos de intervenção que a Ontopsicologia aperfeiçoou ao longo dos anos" (BAZZO et. al., 2011, p. 13).

A Ontopsicologia é uma ciência, um conhecimento existencial, interessando-se por como o homem objetiva a si mesmo e o próprio mundo. Consequentemente, é uma ciência interdisciplinar "que posiciona a própria metodologia a serviço, a disposição da Medicina, da Filosofia, da Economia, da Política, da Estética, muito no âmbito da Arte, e a tudo o que diz respeito à criatividade inventiva do homem em referência ao próprio mundo e à própria sociedade" (MENEGHETTI, 2001, p. 8). É portanto um modelo de conhecimento, um modelo de racionalidade que diz respeito à existência, ao homem e a sua existência, ao homem e o seu mundo, ao homem e a sua sociedade.

\begin{abstract}
Este homem, depois, pode correlacionar, especificar este conhecimento no próprio âmbito empresarial, administrativo, de direito, de política, nos infinitos campos das próprias especificidades de intervenção, no próprio mundo, na própria sociedade, no próprio contexto. (...) Portanto, quando se faz algo que possui um caráter social, ação econômica, é preciso sempre recordar desde o início a especificidade de conhecimento da Ontopsicologia, que é muito prática e imediata, aplicada ao homem. O homem que lê e faz as experiências científicas, que é operador de cultura, operador de ciência. Neste ponto interessa a autenticidade, a exatidão do operador. (MENEGHETTI, 2001, p.8)
\end{abstract}

Nós primeiro devemos alcançar, portanto, a exatidão do homem. Uma vez reestabelecida a exatidão de natureza do homem, este homem pode proceder e fazer conhecimento, pode atuar como operador e vetor de evolução na sociedade. "Neste ponto, nós temos a competência exata. Essa formação consente o nexo ontológico entre indivíduo e problema, entre sujeito e objeto. Uma formação passepartout que pode ser operada no interior de qualquer ciência, sendo portanto interdisciplinar" (AMF, 2013).

No quadro das ciências, a Ontopsicologia difere-se pelo seu objeto específico: o nexo ontológico. É uma formação que consente estabelecer a conexão entre a inteligência do indivíduo, do técnico, do profissional em conexão com a causalidade da vida, da situação, 
de efeitos que operam dentro do homem, da natureza, da sociedade. Meneghetti (2012) explicita essa competência da ciência ontopsicológica, ao descrever os diferenciais de formação da AMF:

\begin{abstract}
Adota-se o critério de como chegar à capacidade de encontrar o nexo ontológico no interior do fato, da experiência da intuição. A intuição não é algo visceral, não é algo de percepção externa, estúpida, mas é um momento que dá o ponto da tomada de comando, o ponto do sucesso. E depois o sujeito preparado tecnicamente o organiza e tem o evento infalível daquele sucesso preestabelecido. Em tudo isso, a nossa formação, que se vale da Escola de Ontopsicologia, dá exatamente a possibilidade de fazer o processo técnico para chegar à tomada imediata no interior daquilo que é a intencionalidade da intuição. E isso é o nexo ontológico que vivemos em relação. (MENEGHETTI, 2012, transcrição de áudio)
\end{abstract}

\title{
6. A DIMENSÃO DA INTERNACIONALIDADE
}

A dimensão da internacionalidade oportuniza um outro escopo fundamental da formação humanista integral: o contato com outras culturas e a relativização dos próprios estereótipos e modelos fixos. A partir da convivência de valor com outras culturas, aprende-se a relativizar tantos estereótipos e tantos absolutos da própria monocultura. Esse relativismo leva a uma curiosidade positiva e abertura de novos horizontes sobre os diversos modos de ser do humano, tolerância e respeito pelos hábitos e valores de outros sistemas culturais (WAZLAWICK, 2014). Conforme enfatiza Meneghetti (2010, p. 249), “a participação em uma pluralidade de situações faz autogênese de inteligência e autoliberação dos estereótipos.”

\begin{abstract}
A questão internacional é muito importante. Eu próprio, quando vejo um inglês, quando vejo um estadunidense, quando vejo um brasileiro, os vejo todos com uma lata na cabeça, com um latão na cabeça. Possuem aquela formação, possuem aquele modo de fazer que já constitui uma sua inferioridade, isto é, existe uma forma de ingenuidade, de pobreza racional no interior deste standard da tradição acadêmica ou operativa dos diversos Estados. Possuem todos um limite territorial da sua nacionalidade, da sua cultura, isto é, o estereótipo cultural base se faz de limite a uma sua interação de relações internacionais. Visto que o business é sempre o ponto frio da realização total, não tem portanto estereótipos, não tem nacionalismos, não tem ideologias etc. Para chegar a ele é importante se despir, relativizar, e isso deve ser de modo aberto. (MENEGHETTI, 2012, transcrição de áudio)
\end{abstract}

Quando se viaja e se encontra outras pessoas e culturas, é possível evadir dos habituais modelos. Quando vemos e contatamos com algo de diferente dos nossos 
estereótipos de civilidade, podemos sair da nossa história para renascer na novidade daquele lugar. Meneghetti (2003, p. 42), ao descrever esta experiência de descobrir novos lugares e culturas, afirma que "quando se tem o impacto com uma nova experiência, devese inventar. Por mais que tenhamos aprendido, é preciso ter sempre a capacidade de aprender o novo."

Essa dimensão da internacionalidade na formação dos jovens no Recanto Maestro é dada também pela formação dos professores, que em sua grande maioria têm formação no exterior (formação acadêmica e experiência prática de mercado) ou por professores internacionais convidados para lecionar na $\mathrm{AMF}$, que trazem as suas vivências e a inteligência daquele país para dentro da sala de aula. Além disso, são oportunizados por meio de convênios internacionais a ida de alunos para fora do país em intercâmbios culturais e profissionais.

No que se refere à formação profissional específica, é importante também conhecer as diversas experiências do mundo sobre o próprio setor, sobre o próprio interesse, sobre o próprio campo. Meneghetti (2013b, p. 451) explica que "o nosso planeta é rico de extraordinárias experiências e, se permanecer sempre na própria casa, se continuará sempre precocemente velhos e fora do jogo da vida". Essa experiência ao exterior não é feita como férias comuns ou necessidade de trabalho, mas com o objetivo de qualificar o próprio interesse e a própria competência competitiva. "Substancialmente, com a experiência feita nos grandes países, se pode entender o original da própria terra. Ir ao exterior, portanto, serve para tornar preciosas as próprias capacidades, mas também os próprios meios" (MENEGHETTI, 2013b, p. 451).

O desenvolvimento da internacionalidade também permite que os jovens conheçam e impactem com o pensamento e obra de expoentes do humanismo perene de diferentes épocas e presente em diferentes países. Meneghetti (2013b) enfatiza que é importante que os jovens se formem por meio de grandes livros, de grandes autores e, depois, por meio de viagens e contatos, impactem pessoalmente com suas obras primas. Existe uma inteligência, a cultura humanista perene, que foi elaborada pelos homens mais representativos das diversas épocas e países. É preciso retomar essa cultura perene do homem para o homem, pois é uma guia que pode garantir segurança para fazer o próprio bem no próprio contexto e situação (MENEGHETTI, 2013a). 


\begin{abstract}
Retornar às fontes clássicas, perenes, pegar o suprassumo de todos os outros países, como, por exemplo, poder-se-ia pegar literatura, cinema, música também de uma cultura plurivalente como a da França, da China, da Federação Russa, dos ingleses. A italiana, no que diz respeito ao Made in Italy, o estilo, a tecnologia verdadeiramente superior. (...) A Itália é o país que gerou o Renascimento, é o país que gerou o Humanismo, isto é, critérios, regras, investigações que autenticam os valores de se ser homem na própria terra. Podese aprender coisas maravilhosas que ainda podem dar um futuro inovador, melhorativo. (MENEGHETTI, 2014a)
\end{abstract}

A cultura humanista é, portanto, uma importante passagem que pode despertar e aguçar a sede pela ciência, pelo saber, em todos os campos. Petry et. al. (2011) destacam que, quando um jovem descobre e se apaixona pelos valores do Humanismo, curiosamente amplia-se o seu terreno de pesquisa e raio de ação. Enquanto o jovem aperfeiçoa a sua profissão, o seu saber fazer bem, abrem-se possibilidades de exploração, de culturas que ele, até aquele momento, não havia pensado ou imaginado. "O resgate dessa cultura humanista pode tornar-se hoje o fundamento da grandeza de um jovem e, consequentemente, de civilização e de progresso social" (PETRY et. al., 2011, p. 46).

Os resultados do Recanto Maestro e seus projetos são também apresentados em eventos e congressos internacionais. Organismos como a UNESCO, a ONU também verificam e acompanham o que é feito no Recanto Maestro, a fim de que essa experiência brasileira possa contribuir com projetos internacionais que são conduzidos e estimulados em todo o mundo. Meneghetti (2012) descreve esse aspecto quando pontua os diferenciais de formação da AMF: “Temos uma relação interna íntima com aquilo que são as máximas organizações, como a ONU, a Unesco. Em que sentido? Não é que nós dependemos. Nós somos operativos no interior como suas pontas de valor, pontas de expressão exemplar a todos os outros" (MENEGHETTI, 2012, transcrição de áudio).

\title{
7. O resultado do protagonismo responsável
}

A formação integral dos jovens no projeto Recanto Maestro, alicerçada na pedagogia ontopsicológica e no desenvolvimento sinérgico e complementar das cinco dimensões descritas anteriormente - estudo, trabalho, alta moralidade, ciência e internacionalidade - tem como resultado o desenvolvimento do protagonismo responsável, conforme ilustra a figura a seguir. 
Figura 1 - Dimensões da formação integral dos jovens realizada no Recanto Maestro

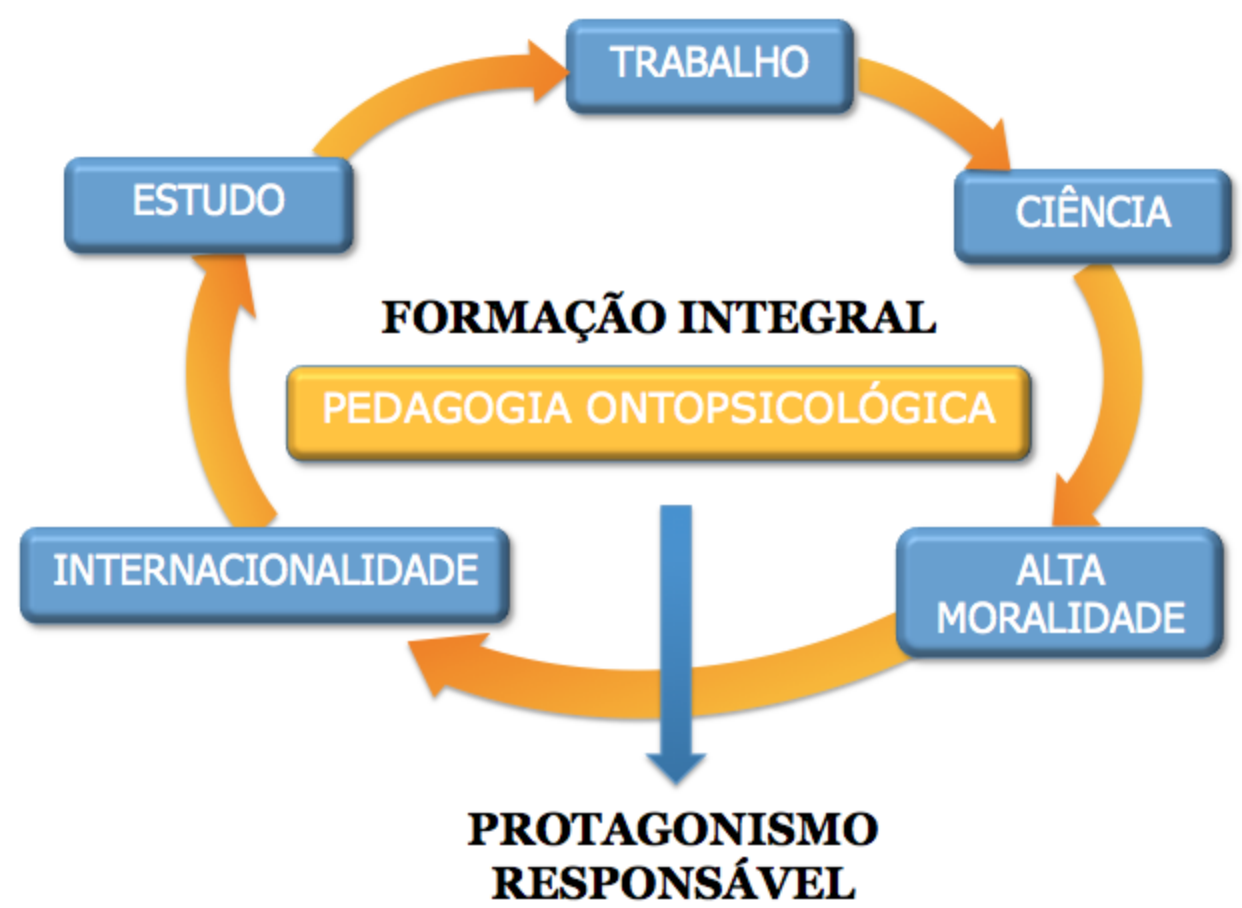

Fonte: autor (2017).

O escopo prático da pedagogia ontopsicológica é "educar o sujeito a fazer e a saber si mesmo: fazer uma pedagogia de si mesmo como pessoa líder no mundo, educar um Eu lógico-histórico com capacidades e condutas vencedoras.” (MENEGHETTI, 2014b, p.14). A pedagogia ontopsicológica tem o objetivo de formar o homem pessoa na função social. Formar o homem cidadão, de modo integral (pessoal, econômico, social, político etc.).

A visão ontopsicológica humanista reconhece que cada ser humano tem intrínseca uma capacidade de autorrealização, independentemente de sua idade, posição social ou contexto. Cada indivíduo tem também inata a possibilidade de construir historicamente o seu projeto de natureza, como protagonista de suas escolhas, conquistas e resultados. "Entende-se que todo o ser humano, portanto, é capaz de agir de modo criativo na existência, atuando o potencial que o especifica e o distingue de todos os outros, segundo o modo como foi previsto pela natureza. A realização de si mesmo é a principal tarefa existencial de cada indivíduo" (FUNDAÇÃO ANTONIO MENEGHETTI, 2016, p. 21). 
O conceito-chave que sustenta essa pedagogia é o da responsabilidade em relação à própria identidade, ou seja, desenvolver e atuar as próprias potencialidades inatas. Ser responsável não é uma escolha, mas um fato que não pode ser eliminado a partir do momento em que se existe. "Para tanto, faz-se necessária uma pedagogia que leve o jovem a conhecer a si mesmo e a adquirir os instrumentos técnico-práticos e racionais para historicizar sua liderança e proporcionar o desenvolvimento humanista no contexto social em que atua" (BAZZO et. al., 2011, p. 12). Temos desse modo o protagonismo responsável:

\begin{abstract}
$\mathrm{Na}$ condução de uma obra, o protagonista é a pessoa de destaque, o agente principal, responsável por projetar as inúmeras funções de trabalho para o sucesso e o êxito do todo. A responsabilidade, por sua vez, implica assumir o dever de criar um modo de manter-se e crescer sem pretender a própria solução por meio dos outros. A responsabilidade primária refere-se à própria vida: primeiro, tenho que responder às exigências que constroem meu valor como pessoa. Em primeiro lugar, há o dever de responder de modo excelente à provocação de construir a si mesmo. Protagonista responsável é, portanto, aquele que sabe, na relação humana, estabelecer a ordem de funções para cultivar o crescimento das pessoas sem impedir a autonomia pessoal. (...) A liderança é sempre o resultado da escolha contínua e da ação responsável de cada indivíduo, em coerência com seu próprio potencial. Cada ação acertada concretiza os horizontes amplificados, que, depois, tornam-se providência aos próximos. Providência em sentido prático, útil e funcional, seja na arte, na política, na jurisprudência ou na alta tecnologia. Essa estrada pedagógica, que se aprende cotidianamente, deve ser recolocada no interno dos nossos sistemas educativos, ensinando a cada indivíduo como construir a própria dignidade. (FUNDAÇÃO ANTONIO MENEGHETTI, 2016, p. 22)
\end{abstract}

Esse é o ponto, conforme enfatiza Meneghetti na sua fala de inauguração da AMF: “criar uma escola de formação superior, significa que no futuro estes jovens deverão dar também testemunho de vida sadia, em sentido biológico, racional, em sentido social" (MENEGHETTI, 2015a, p. 85). O Centro Internacional de Arte e Cultura Humanista Recanto Maestro, por meio dos seus inúmeros projetos epicentrados na Antonio Meneghetti Faculdade, busca recolocar o homem no centro de todas as coisas, como quer que seja a racionalidade do nosso sistema. "Este é o verdadeiro movente, e é um verdadeiro grande prazer investir arte, vida, dinheiro, e o que servir, para ser genitores, mestres de espírito, a grandes que terão orgulho de se terem feitos sozinhos, de terem merecido sozinhos, grandes que souberam responder às ocasiões de vida, da sociedade e da escola” (MENEGHETTI, 2015a, p. 85). 


\section{CONSIDERAÇÕES FINAIS}

Com o intuito de resgatar passagens teóricas e práticas sobre a formação de jovens no Centro Internacional de Arte e Cultura Humanista Recanto Maestro, esta pesquisa de desenvolvimento teórico identificou cinco dimensões dessa formação integral - o estudo, o trabalho, a alta moralidade, a ciência e a internacionalidade - que permitem o desenvolvimento do protagonismo responsável do jovem.

A pesquisa foi motivada pelo momento em que vive a instituição criada por Antonio Meneghetti - o seu aniversário de 10 anos - a fim de que este conhecimento possa auxiliar no reforço do núcleo do projeto, com consequente expansão autêntica e conforme à sua identidade original.

A Antonio Meneghetti Faculdade, enquanto coração do Recanto Maestro e epicentro de todos os seus projetos de educação, tem um papel fundamental. Pesquisas como esta que auxiliem a resgatar e levar adiante a essência formalizada por seu idealizador podem ser de grande auxílio no crescimento deste grande projeto humanista, que pode ser estímulo e motor de evolução não apenas ao Brasil, mas também a todo o planeta.

Somos hóspedes responsáveis neste planeta Terra, nem os únicos nem absolutos, mas um componente do grande projeto da vida. É importante compreender qual é a arte de nascer e crescer neste planeta. É necessário encontrar uma sintonia, uma convergência, entre o projeto da vida e a pequena realidade de cada homem, em particular, a realidade das crianças e dos jovens. Eles são, de fato, o amanhã de cada ser humano. O homem viverá no tempo e na história se os jovens tiverem aprendido alguma coisa pela qual serem grandes por si mesmos. Na medida em que os jovens forem grandes, capazes, também os outros seres humanos estarão junto com eles no futuro do tempo neste planeta (MENEGHETTI, 2014b, p. 194). 


\section{REFERÊNCIAS}

ANTONIO MENEGHETTI FACULDADE (AMF). Vídeo Nexo Ontológico. Recanto Maestro: Antonio Meneghetti Faculdade, 2013.

ANTONIO MENEGHETTI FACULDADE. Centro Poliesportivo Educacional Recanto Maestro: Premissas. Recanto Maestro: Antonio Meneghetti Faculdade: 2017 (no prelo).

BAZZO, P.; ROCKENBACH, G.; SCHAEFER, R.; SCHUTEL, S. Identidade Jovem: il progetto che coinvolge i giovani nel promuovere gli obiettivi del millennio (MDGs). In: Revista Nuova Ontopsicologia, ano XXIX, n. 1. Roma: Psicologica Editrice, 2011.

FUNDAÇÃO ANTONIO MENEGHETTI. Posicionamento Institucional. Anais II Cong. Int. Uma Nova Pedagogia para a Sociedade Futura. Recanto Maestro: Fundação Antonio Meneghetti, 2016.

MENEGHETTI, A. A especificidade da Ontopsicologia (conferência em vídeo). Recanto Maestro, 2001. Acervo Audiovisual Fundação Antonio Meneghetti. Acesso em 18/04/17.

MENEGHETTI, A. OntoArte: o Em Si da arte. Florianópolis: Ontopsicológica, 2003.

MENEGHETTI, A. Aprendiz líder. São Paulo: FOIL, 2009.

MENEGHETTI, A. Manual de Ontopsicologia. 4. ed. Recanto Maestro: Ontopsicológica, 2010.

MENEGHETTI, A. Cinelogia "Educação" (conferência em vídeo). Recanto Maestro, 2011a. Acervo Audiovisual Fundação Antonio Meneghetti. Acesso em 18/04/17.

MENEGHETTI, A. O Projeto Homem. 3. ed. Recanto Maestro: Ontopsicológica, 2011b.

MENEGHETTI, A. Os diferenciais da AMF (gravação em áudio). Calipso, 2012. Acervo Audiovisual Fundação Antonio Meneghetti. Acesso em 18/04/17.

MENEGHETTI, A. Os jovens e a ética ôntica. Recanto Maestro: Ontopsicológica, 2013a.

MENEGHETTI, A. Psicologia empresarial. São Paulo: FOIL, 2013 b.

MENEGHETTI, A. Depoimento sobre o Brasil e a Cultura Humanista In: ASSOCIAÇÃO BRASILEIRA DE ONTOPSICOLOGIA. Antonio Meneghetti: maestro para a cultura humanista brasileira. Recanto Maestro: ABO, 2014a.

MENEGHETTI, A. Pedagogia ontopsicológica. 3. ed. Recanto Maestro: Ontopsicológica, 2014b.

MENEGHETTI, A. Formação à responsabilidade. In: ASSOCIAÇÃO BRASILEIRA DE ONTOPSICOLOGIA. Cultura \& Educação: uma nova pedagogia para a sociedade futura. Recanto Maestro: Ontopsicológica Editora Universitária, 2015a. 
MENEGHETTI, A. Uma pedagogia para o homem líder. In: ASSOCIAÇÃO BRASILEIRA DE ONTOPSICOLOGIA. Cultura \& Educação: uma nova pedagogia para a sociedade futura. Recanto Maestro: Ontopsicológica Editora Universitária, 2015b.

MENEGHETTI, A. O Residence Ontopsicológico. 4. ed. Recanto Maestro: Ontopsicológica, 2016.

PELLEGRINI, B.; PETRY, A. O sentido do trabalho para o líder. 2010. $15 \mathrm{f}$. Monografia: Especialização em Gestão de Negócios e Intuição - Antonio Meneghetti Faculdade, Recanto Maestro, 2010.

PETRY, A. M.; OLIVEIRA, G. R.; SCHAEFER, R. A forma mentis de uma sociedade sustentável: uma proposta de formação de jovens. In: Anais Cong. Int. Responsabilidade e Reciprocidade. Recanto Maestro: Fundação Antonio Meneghetti, 2011.

PETRY et. al. A formação humanista de jovens como garantia de sustentabilidade, identidade e protagonismo civil. PRONAC n. 098244. Recanto Maestro: Associação Brasileira de Ontopsicologia, 2011.

ROCCO, V. Autossustento: o primeiro dever de um jovem. In: Revista Nova Ontopsicologia, ano XXIV, n. 1. Recanto Maestro: Ontopsicologica Editrice, 2006.

VIDOR, 2016. Depoimento sobre o diferencial da Ontopsicologia na formação dos jovens. In: Vídeo institucional "Formação em Recanto Maestro". Recanto Maestro: Fundação Antonio Meneghetti, 2016.

WAZLAWICK, P. Para engendrar a técnica de personalidade: resultados da pedagogia ontopsicológica aplicada na formação pessoal e profissional de jovens no ensino superior universitário. 2014. Monografia: Especialização em Gestão do Conhecimento e o Paradigma Ontopsicológico - Antonio Meneghetti Faculdade, Recanto Maestro, 2014. 